\title{
Bioactive Titanium-Hydroxyapatite Composites by Powder Metallurgy Route
}

\author{
Emani Siva Krishna ${ }^{1}$ (D), Gamini. Suresh ${ }^{1}$ (D) \\ 1 Department of Mechanical Engineering, Vignan's Foundation for Science, Technology \& Research, Vadlamudi 522213, \\ India; sivakrishna.emani@gmail.com (E.S.K.);drgs.mech@gmail.com (G.S.); \\ * Correspondence: sivakrishna.emani@gmail.com (E.S.K.);
}

Scopus Author ID 57194163209

Received: 8.07.2021; Revised: 20.08.2021; Accepted: 25.08.2021; Published: 18.10.2021

\begin{abstract}
Titanium (Ti) and its alloys have become the most promising biomaterials due to their low elastic modulus, high corrosion resistance, and relatively long-lasting ability in a physiological environment. Bioactive implants enhance the tissue interactions at the surface of the implants and promote a higher healing rate. However, titanium exhibits bio-inert nature. Hence in the present study, hydroxyapatite (HA), a well-known bioceramic, has been selected to disperse into Ti with an aim to develop bioactive Ti-based implants. Ti-HA composites with 5\% and 10\% HA were successfully produced by high-energy ball milling for $20 \mathrm{~h}$ followed by sintering (at $850{ }^{\circ} \mathrm{C}$ ). Fine-grained composites were successfully produced and were found to be free from any impurities. The composites were immersed in simulated body fluid (SBF) for 4 weeks to investigate the in vitro bioactivity. From the XRD studies and scanning electron microscope observations, the presence of $\mathrm{HA}$ in the composite enhanced the bioactivity as reflected with higher $\mathrm{Ca} / \mathrm{P}$ mineral phases on the surface of the composites compared with pure Ti substrate. From the results, it can be concluded that the bioactive nature of $\mathrm{Ti}$ can be enhanced by reinforcing HA to manufacture medical implants with a higher healing rate.
\end{abstract}

Keywords: titanium; hydroxyapatite; bioactivity; composite; biomineralization; wettability.

(C) 2021 by the authors. This article is an open-access article distributed under the terms and conditions of the Creative Commons Attribution (CC BY) license (https://creativecommons.org/licenses/by/4.0/).

\section{Introduction}

Titanium (Ti) and its alloys are the important materials to manufacture orthopedic implants owing to their promising properties compared with steels and Co alloys [1]. Titanium exhibits significantly lower young's modulus than steel implants and helps reduce stress shielding phenomena, which is usually associated with the metallic implants that possess higher young's modulus than bone [2-4]. Ti also reduces the difficulty in diagnosing patients using MRI scanning as Ti is non-magnetic compared with steel implants. The corrosion resistance of $\mathrm{Ti}$ is relatively higher in the physiological solutions and gives longer life to the implant. However, Ti suffers from insufficient bio-activity, which can strongly bond with the local hard tissue $[5,6]$. From the context of load-bearing requirements, Ti and its alloys possess sufficient mechanical properties, and no further improvement is sought to increase mechanical strength. Whereas in the context of tissue interactions with the implant surface, there exists a need to develop tailored surfaces to promote a higher healing rate. Several strategies, such as providing surface coatings, surface chemical treatments, microstructure modifications, etc., have been adopted to improve the bioactivity of Ti [7-12].Furthermore, the surface of titanium implants was tailored by providing special coatings to exhibit anti-infection properties, antibacterial properties, better cell response, and improved bioactivity [13-16]. It is also reported that the 
porosity, surface morphology, texture, and surface energy significantly influence the cell adhesion mechanisms at the surface of biomedical implants [17-19]. On the other hand, altering the composition of the implant by adding appropriate reinforcing particles into $\mathrm{Ti}$ is a promising strategy that enhances the bioactivity of the implant. This route also eliminates the issues associated with the bonding quality between the coating layer and the Ti substrate. A few earlier reports demonstrate using hydroxyapatite as a coating material or dispersing phase to produce bioactive composites [20-23]. These studies demonstrate developing Ti-based functionally graded materials through powder metallurgy. High energy ball milling is a powder processing technique that helps to reduce the particle size and to mix the powders uniformly [24]. In addition to uniformly mixing the powders, mechanical alloying of powders can also be done by high-energy ball milling. Hydroxyapatite (HA) is a ceramic phase of calcium and phosphorous usually found in natural bone in the form of nanocrystals [25]. Therefore, adding HA to Ti helps to promote better cell activities at the implant surface, which further leads to a higher healing rate. Earlier reports demonstrate the positive effect of the addition of HA to different implant materials on improving cell adhesion and proliferation [26-28]. Hence, in the present work, lab-prepared nano-HA powder was selected to disperse Ti by ball milling followed by sintering. Then the role of added HA on enhancing the wettability and bioactivity was assessed by in vitro bioactivity studies conducted using simulated body fluid.

\section{Materials and Methods}

Pure Ti powder (Merc, India) with an average particles size of $114 \pm 6.2 \mu \mathrm{m}$ was used as the starting material. Lab-prepared nano-HA was used as reinforcement material in the present work. The composition of 5\% and $10 \% \mathrm{HA}$ (by wt.) remaining pure Ti was prepared, and ball milled for $20 \mathrm{~h}$. Ball milling was carried out using a tungsten carbide vial of $80 \mathrm{ml}$ volume and tungsten carbide balls of $10 \mathrm{~mm}$ dia. The powder to ball weight ratio was maintained as 20:1. Ball milling was done in ethanol medium. For every $1 \mathrm{~h}$ of ball milling, 30 min idle time was given to cool the equipment. The ball-milled powders were consolidated in a hydraulic press by applying a $200 \mathrm{MPa}$ load with a pellet size of $10 \mathrm{~mm}$ dia. Then the green composites were sealed in vacuum tubes and sintered in a box furnace at $850{ }^{\circ} \mathrm{C}$. Figure 1 schematically explains the sequence of steps involved in developing Ti-HA composite in the present work.

Commercially available pure titanium (CP-Ti, grade 2) was also used to compare with the produced composites (Ti-5HA and Ti-10HA). All the samples were polished as per the standard metallographic protocol and etched with Kroll's reagent. Microstructural observations were done by using an optical microscope and electron microscope (SEM, TESCON, Czech Republic) attached with an energy-dispersive X-ray (EDS) facility. Nano-HA crystals were characterized by transmission electron microscope (TEM, FEI, USA). All the samples were subjected to X-ray diffraction analysis (D8, Bruker, USA). In order to assess the surface wettability of the samples, water contact angle measurements were done on the surface of all the samples by using distilled water $(2 \mathrm{ml})$ as the solvent. Then the bioactivity of the samples was investigated by immersion studies carried out in simulated body fluid (SBF). The procedure and the ion concentration of SBF can be referred to elsewhere [29, 30]. Each sample was immersed in a solution of $50 \mathrm{ml}$, and the containers were placed in a water bath that was maintained at $37^{\circ} \mathrm{C}$ for 4 weeks. Then the samples were collected and gently rinsed with distilled water and dried in the open air. The surface of the immersed samples was subjected to 
SEM and XRD studies to analyze the mineral phases which were deposited on the surface from the SBF.

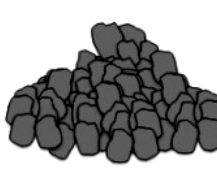

Titanium powder

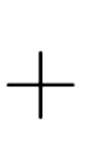

Nano-hydroxyapatite

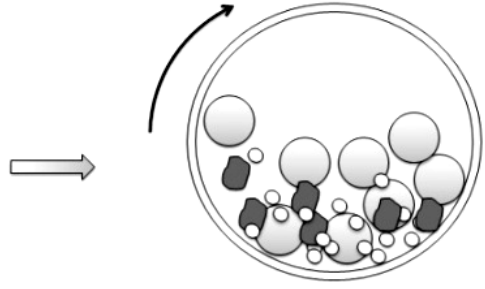

Ball milling
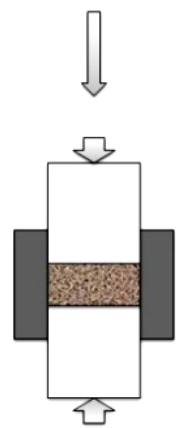

Compaction

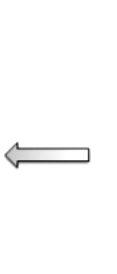

Compactic

Ti-HA composite

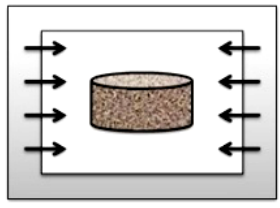

Sintering

Figure 1. Schematic illustration of developing Ti-HA composites by ball milling and sintering.

\section{Results and Discussion}

The optical microscope image of $\mathrm{CP}-\mathrm{Ti}$ is shown in Figure 2 (a). From the microstructure, the average grain size was measured as $43 \pm 4.7 \mu \mathrm{m}$. Figure 2 (b) shows the SEM image of pure Ti powder used in the present study. The corresponding EDS analysis (Figure 2 (c)) confirms the elemental composition in the procured Ti powder. The Ti particles were observed with irregular shapes. From the TEM image of nano-HA, the crystals were observed with acicular morphology with significant length $(67 \mathrm{~nm})$ to thickness $(25 \mathrm{~nm})$ variation. The corresponding SAED pattern shows the appearance of spots as ring structures, which is a typical pattern for nanocrystals. These observations confirm the nanocrystalline nature of the HA used in the present work to develop $\mathrm{Ti}-\mathrm{HA}$ composites.

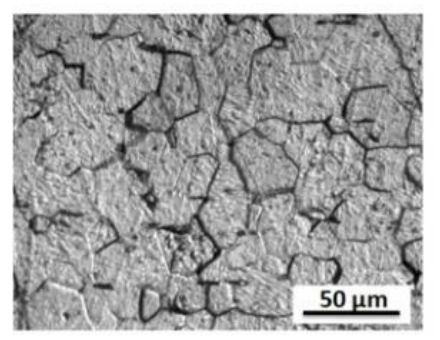

(a)

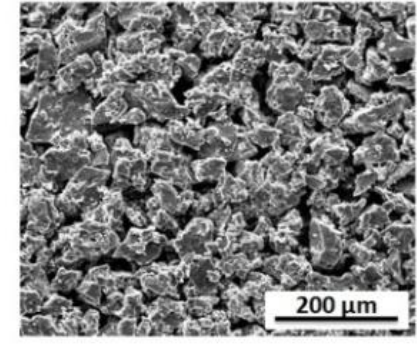

(b)

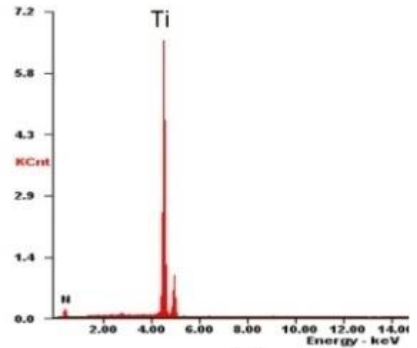

(c)

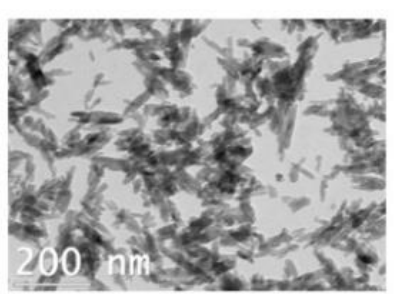

(d)

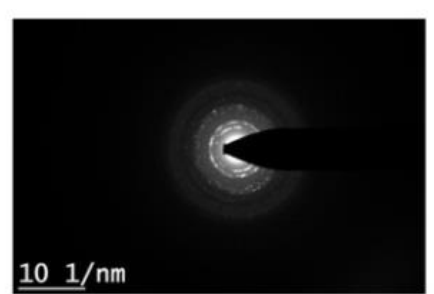

(e)

Figure 2.(a) microstructure of pure Ti, (b) SEM image of Ti powder, (c) corresponding EDS analysis, (d) TEM bright field image of nano-HA, and (e) corresponding selective area electron diffraction (SAED) pattern. 
From the XRD analysis (Figure 3), the crystallite size of nano-HA was calculated as 48 $\mu \mathrm{m}$, which also confirms the nano-level of the HA used in the present work and supports the TEM observations of HA. Typical XRD of Ti-10HA shows all the peaks corresponding to Ti and peaks corresponding to HA. Additionally, no new peaks were identified apart from the peaks corresponding to $\mathrm{Ti}$ and HA, confirming that the HA phase added to Ti was stable after sintering. The stability of HA is crucial to retain the benefits of adding HA to Ti in developing these composites.

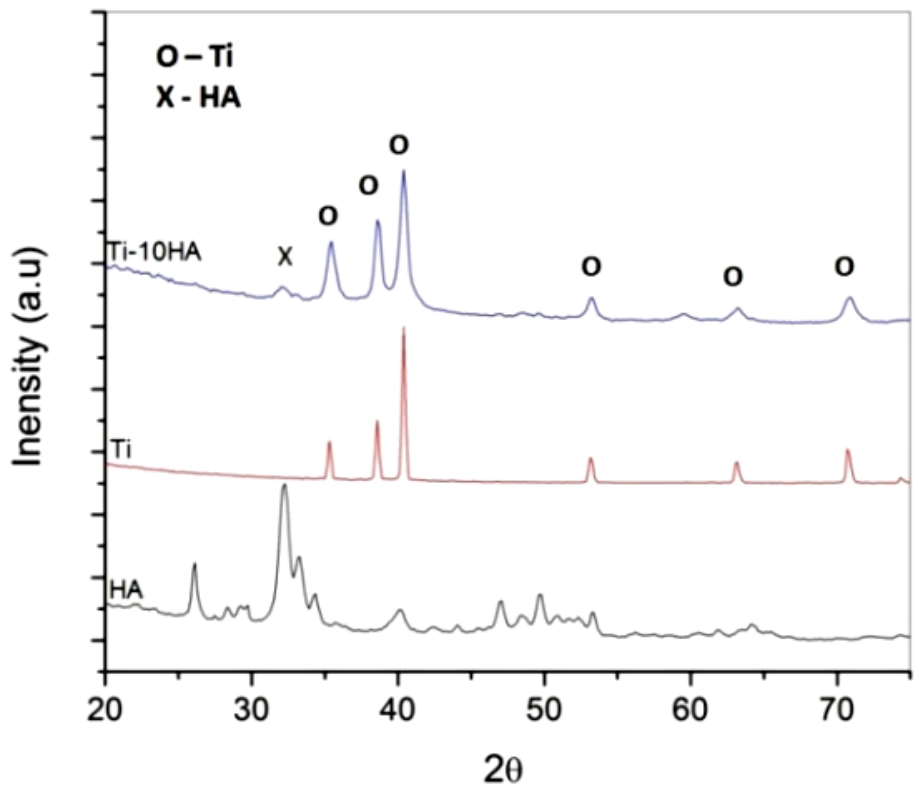

Figure 3. XRD analysis of the samples.

Usually, HA is stable up to $1000{ }^{\circ} \mathrm{C}$ without any phase transformation. Since the sintering temperature in the present work was $850{ }^{\circ} \mathrm{C}$, no degradation of $\mathrm{HA}$ to any other unusual phase is expected. Figure 4 shows the microstructure of sintered Ti-HA composites. The grain size was measured as $2.3 \pm 0.7 \mu \mathrm{m}$ and $1.9 \pm 0.6 \mu \mathrm{m}$ for Ti-5HA and Ti-10HA, respectively. A few grains with sub-micrometer levels were also observed. The grain refinement observed in the composites can be attributed to the size reduction of $\mathrm{Ti}$ particles during the ball milling. It is reported that ball milling for longer periods significantly decreases the particles' size and results in nanocrystals [24]. As observed in the present work, decreased particle size after high-energy ball milling helped achieve a smaller grain size after sintering.

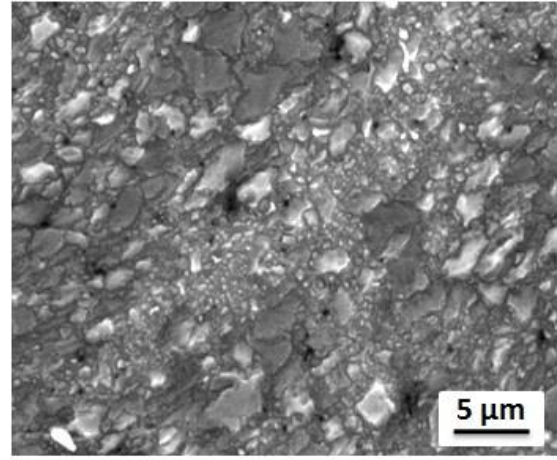

(a)

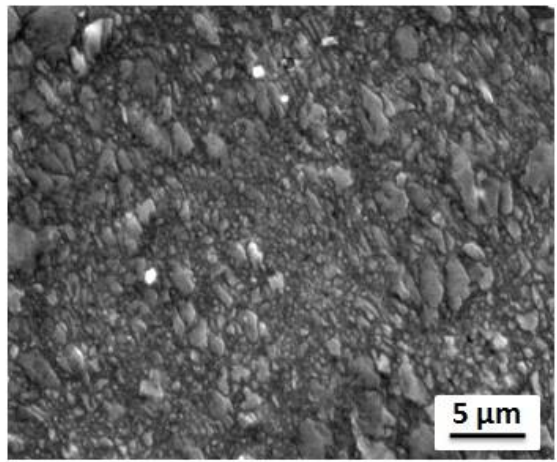

(b)

Figure 4. SEM observations: (a) Ti-HA and (b) Ti-10 HA composite.

The contact angle measurements revealed the increased wettability for the composites compared with CP-Ti. Figure 5 shows the typical photographs of water droplets on the surface 
of the samples. Contact angle $(\theta)$ was measured for the samples and listed in Table 1. All the samples exhibited hydrophilic nature as reflected from the lower contact angles $(\theta)$. It is desired to have more hydrophilicity for the surfaces of implants to promote wettability. Surfaces with high wettability enhance biomineralization and cell adhesion and promote a high healing rate $[31,32]$. Lower contact angles were measured for the composites compared with CP-Ti, indicating higher wettability for the composites than CP-Ti. The presence of bioactive nanophases at the surface also promotes a higher rate of cell regeneration and growth [31].

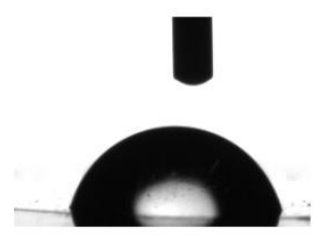

(a)

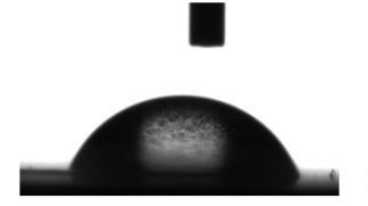

(b)

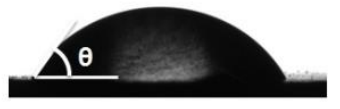

(c)

Figure 5. Photographs of water droplets on the samples: (a) CP-Ti, (b) Ti-5HA, and (c) Ti-10HA.

Table 1. Contact angles of the samples.

\begin{tabular}{|c|c|c|}
\hline S.No. & Sample & Contact angle $(\theta)$ \\
\hline 1 & CP-Ti & $64.5 \pm 3.2$ \\
\hline 2 & Ti-5HA & $59.1 \pm 2.8$ \\
\hline 3 & Ti-10HA & $57.2 \pm 1.7$ \\
\hline
\end{tabular}

The surface morphologies and corresponding EDS analysis of the samples after 4 weeks of immersion in SBF are shown in Figure 6. Deposition of mineral phases on the surface of the immersed samples can be seen, and the corresponding EDS analysis confirms the presence of $\mathrm{Ca}$ and $\mathrm{P}$ elements in addition to $\mathrm{Ti}$. The presence of $\mathrm{Ca}$ and $\mathrm{P}$ suggests the formation of calcium-based mineral phases on the surface of the SBF. XRD analysis (Figure 7) also confirms the deposited phases as hydroxyapatite. Higher wettability and presence of nano-HA in the composite accelerated mineral deposition from the SBF. Usually, smaller grain size is associated with a larger fraction of grain boundary. Grain boundaries are high-energy regions, and therefore, fine grain structure gives higher surface energies. Therefore, the nucleation of apatite crystals from the SBF is accelerated at the high-energy sites. Furthermore, nano-HA in the composites acts as nuclei and contributes to the growth of apatite from the SBF. This is similar to the reported work developing bioactive composites by using nano-HA as dispersing phase [33]. Furthermore, nano-HA's presence was found to be influential in enhancing the tissue response for quick healing due to the osseointegration exhibited by nano-HA. Therefore, smaller grain size, increased wettability, and presence of nano-HA in the composites improved the $\mathrm{Ca} / \mathrm{P}$ mineral phase deposition, indicating increased bioactivity. Figure 8 shows the deposition of the $\mathrm{Ca} / \mathrm{P}$ mineral phase as a thick layer on a selective region of Ti-10HA. These findings suggest that the Ti can be made bioactive by incorporating a sufficient amount of HA.

The present study successfully demonstrates producing Ti-HA composite by powder metallurgy route. The need for bioactive titanium to manufacture bone fixing plates, screws, and dental implants is growing to promote a higher healing rate. Bioactivity is a phenomenon connected with the surface of the implant and the tissue. Hence, providing surface coatings may improve the bioactivity as the tissue interactions with the implant are initiated from the surface. However, the success of the coating depends on the quality of the coating and the bonding level between the implant substrate and the coating material. 


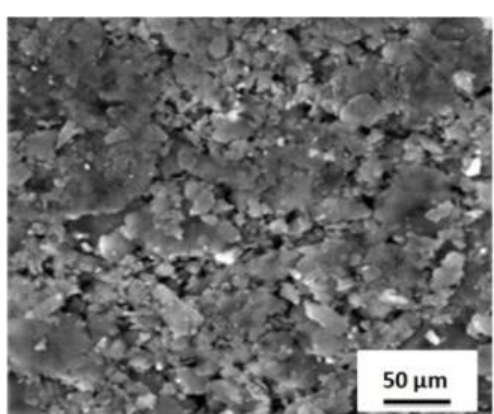

(a)

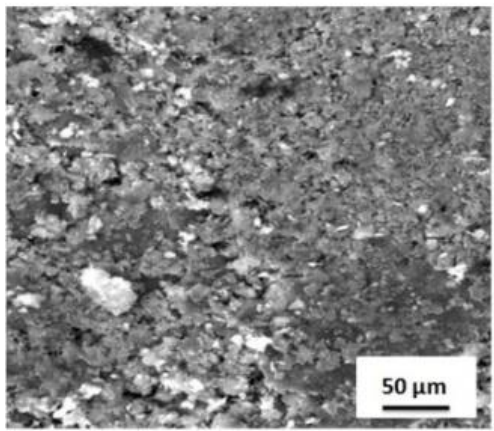

(c)

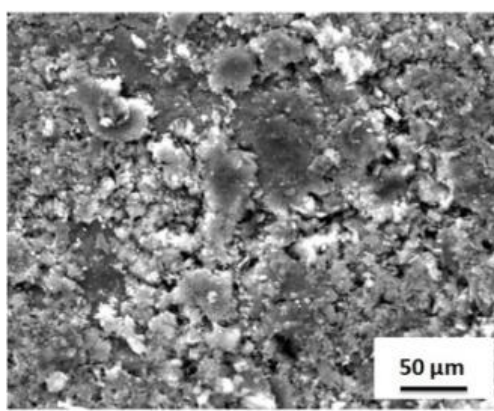

(e)

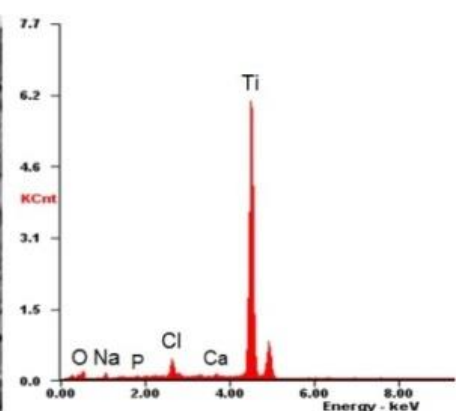

(b)

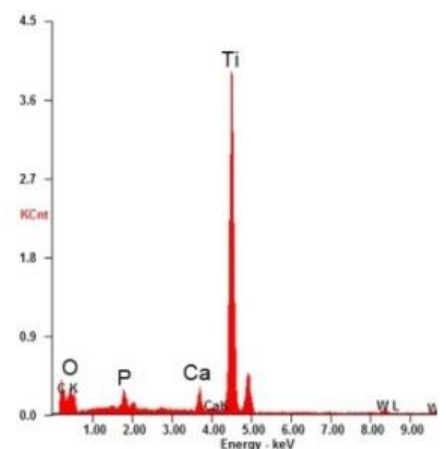

(d)

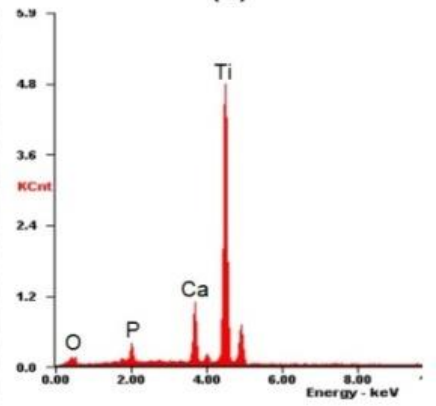

(f)

Figure 6. SEM observations of the surface of the samples after immersion (4 weeks): (a) CP-Ti, (b) corresponding EDS analysis, (c) Ti-5HA, (d) corresponding EDS, (e) Ti-10HA and corresponding EDS analysis.

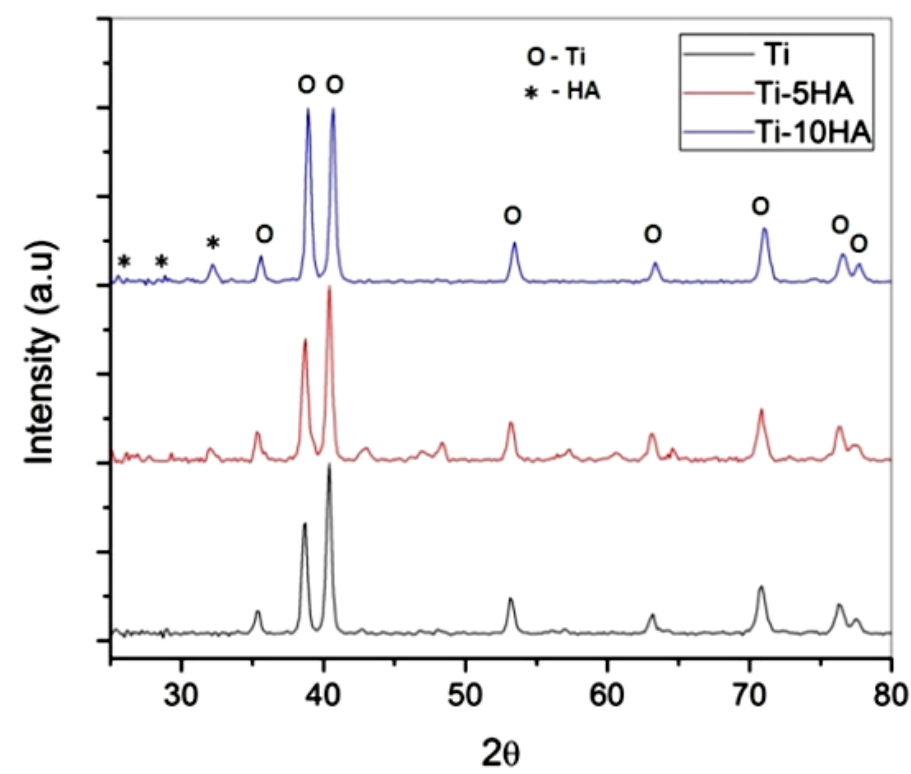

Figure 7. XRD patterns of immersed samples (4 weeks). 


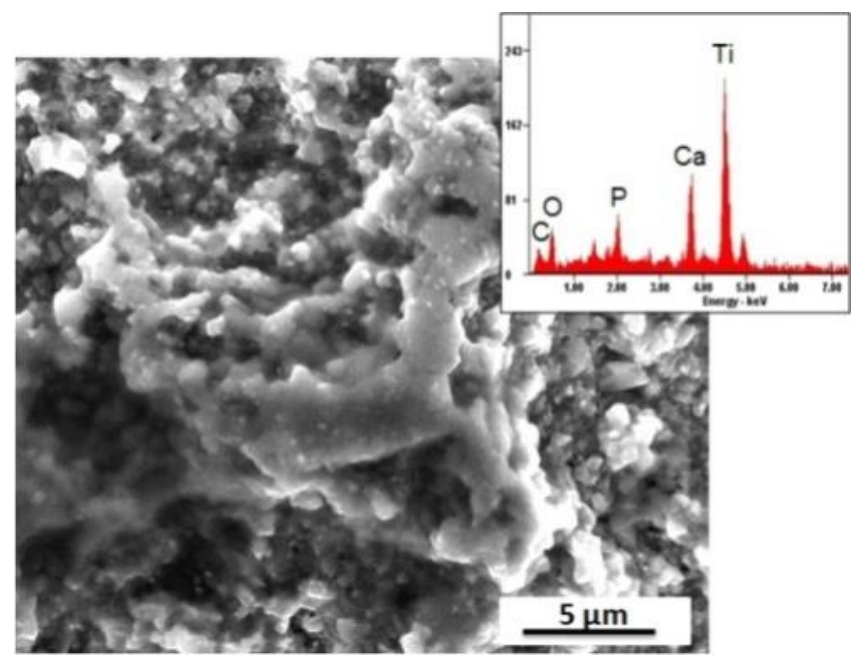

Figure 8. SEM image and corresponding EDS analysis of Ti-HA sample after 4 weeks of immersion in SBF.

Particularly for implants where temperature variations are common, the coated material (ceramic) and the substrate (metal) experience different levels of thermal expansions due to the mismatch in thermal properties, and the bonding between the coating material and the implant is affected and may lead to failure of the coating. For example, in dental implants, where consuming cold and hot beverages gives a considerable change in the temperature, the coating on the implant may fail due to the aforementioned reason. Therefore, producing the Ti implant with inherent bioactivity property by incorporating bioactive imparting phases into the implant can be a viable strategy. As demonstrated in the present work, adding nano-HA as a reinforcing phase to manufacture Ti-HA composite helps produce implants with enhanced bioactivity. As the content of HA is increased to $10 \%$, the effect was observed as higher. Further investigations on finding the role of added nano-HA on mechanical properties are needed to be studied to manufacture bioactive Ti-HA implants.

\section{Conclusions}

The present work incorporated nano-hydroxyapatite (HA) powder into Ti by highenergy ball milling and sintering to develop bioactive Ti-based implants. No significant contamination and impurity was observed in the composites from the XRD analysis. Compared with the starting particle size, the average grain size of the sintered composite was significantly decreased. Contact angle measurements confirmed the increased wettability for the composites compared with reference CP-Ti. From the bioactivity studies conducted in SBF for 24 days, a higher rate of mineral deposition was observed on the surface of Ti-HA composites, and the effect was more on the Ti-10 HA composite. Smaller grain size increased wettability, and the addition of nano-HA were the prominent reasons behind the enhanced bioactivity, as reflected from the deposition of more $\mathrm{Ca} / \mathrm{P}$ mineral phase from the $\mathrm{SBF}$. Hence, it can be concluded that by dispersing HA, bioactive Ti-based implants can be successfully produced through the powder metallurgy route to manufacture implants for bone and dental applications.

\section{Funding}

This research received no external funding. 


\section{Acknowledgments}

The authors would like to thank Dr. M. Ananda Rao, Principal Scientist, CSIR-NML Madras Complex, Chennai, India, for allowing to use ball milling facility. The authors also thank Mr. B. Venkateswarlu, Assistant Professor, Dept of MME, IIIT Nuzvid, India, for helping in material characterization.

\section{Conflicts of Interest}

The authors declare no conflict of interest.

\section{References}

1. Kaur, M.; Singh, K. Review on Titanium and Titanium Based Alloys as Biomaterials for Orthopaedic Applications. Mater. Sci. Eng. C2019, 102, 844-862, https://doi.org/10.1016/j.msec.2019.04.064.

2. Nicholson, J. W. Titanium Alloys for Dental Implants: A Review. Prosthesis 2020, 2, 100-116, https://doi.org/10.3390/prosthesis2020011.

3. Zhang, L. C.; Chen, L. Y. A Review on Biomedical Titanium Alloys: Recent Progress and Prospect. Adv. Eng. Mater. 2019, 21, 1801215,https://doi.org/10.1002/adem.201801215.

4. Chen, L. Y.; Cui, Y. W.; Zhang, L. Ch. Recent Development in Beta Titanium Alloys for Biomedical Applications. Metals 2020, 10, 1139, https://doi.org/10.3390/met10091139.

5. Jemat, A.; Ghazali, M. J.; Razali, M.; Otsuka, Y. Surface Modifications and Their Effects on Titanium Dental Implants. Bio. Med. Research. Intl.2015, 791725,https://doi.org/10.1155/2015/791725.

6. Geetha, M.; Singh, A. K.; Asokamani, R.; Gogi, A. K. Ti Based Biomaterials, the Ultimate Choice for Orthopaedic Implants - A Review. Prog. Mater. Sci.2009, 54, 397-425.

7. Wen, C. Surface Coating and Modification of Metallic Biomaterials, Elsevier, Cambridge, UK, 2015, pp 423431,https://doi.org/10.1016/B978-1-78242-303-4.18001-9.

8. Truong, V. K.; Stuart, R.; Lapovok, R.; Estrin, Y.; Wang, J. Y.; Berndt, C. C.; Barnes, D. G.; Fluke, C. J; Crawford, R. J.; Ivanova, E. P. Effect of Ultra Fine-Grained Titanium Surfaces on Adhesion of Bacteria. Appl. Microbiol. Biotechnol. 2009, 83, 925-937,https://doi.org/10.1007/s00253-009-1944-5.

9. Ratna Sunil B.; Thirugnanam A.; Chakkingal, U.; Sampath Kumar, T. S. Nano and Ultra Fine Grained Metallic Biomaterials by Severe Plastic Deformation Techniques. Mater. Technol. 2016, 31, 743755,https://doi.org/10.1080/10667857.2016.1249133.

10. Thomas, K. A.; Swati, D.; Sultana, N.; Sarkar, K.; Shubhabrata, D. Design of Ti Composite with Bioactive Surface for Dental Implant. Mater. Manuf. Proces. 2020, 3, 643-651, https://doi.org/10.1080/10426914.2020.1711927.

11. Yang, K.; Wang, J.; Tang, H.; Li, Y. Additive Manufacturing of In-Situ Reinforced Ti-35Nb-5Ta-7Zr (TNTZ) Alloy by Selective Electron Beam Melting (SEBM). J. Alloys Compd. 2020, 826, 154178, https://doi.org/10.1016/j.jallcom.2020.154178.

12. Yadav, P.; Saxena, K.K. Effect of Heat-Treatment on Microstructure and Mechanical Properties of Ti Alloys: An Overview. Mater. Today Proc. 2020, 26, 2546-2557.

13. Toirac, B.; Amaya, G. C,; Sandra, C. C.; John, J. A. C.; Jaime, E.; Aranzazu, M.; Antonia, J. M. Electrochemical Characterization of Coatings for Local Prevention of Candida Infections on Titanium-Based Biomaterials. Prog. Org. Coat.2020, 146, 105681, https://doi.org/10.1016/j.porgcoat.2020.105681.

14. Daniel, M.; Yordan, H.; Rolf, M.; Michael, K.; Johann, P. R.; Cyril, P.; Margarita, D. A. Influence of Surface Termination of Ultrananocrystalline Diamond Films Coated on Titanium on Response of Human Osteoblast Cells: A Proteome Study. Mater. Sci. Eng. C, 2021, 128, 112289, https://doi.org/10.1016/j.msec.2021.112289.

15. Alejandra, R.C.; Diego, T.; Belal, R.; Monica, O. H.; Maria, P. G.; José, A. C.; José, M. M.; Elisa, R. Bioactivity and Antibacterial Properties of Calcium- and Silver-Doped Coatings on 3D Printed Titanium Scaffolds. Surf. Coat. Technol.2021, 421, 127476, https://doi.org/10.1016/j.surfcoat.2021.127476.

16. Hyun, S.K.; Sangamesh, G. K.; Syam, P. N. Biomaterial-Directed Cell Behavior for Tissue Engineering.Curr. Opin. Biomed Eng.2021, 100260, https://doi.org/10.1016/j.cobme.2020.100260. 
17. He, Y.; Li, Z.; Ding, X.; Xu, B.; Wang, J.; Li, Y.; Chen, F.; Meng, F.; Song, W.; Zhang, Y. Nanoporous Titanium Implant Surface Promotes Osteogenesis by Suppressing Osteoclastogenesis via Integrin B1/Fakpy397/MAPK Pathway. Bioact. Mater2021, https://doi.org/10.1016/j.bioactmat.2021.06.033.

18. Jefferson, O. A.; Negin, F.; Tyler J. H.; Jamelle, S.; Lais, Morandini.; Rene, O. N. Control of Innate Immune Response by Biomaterial Surface Topography, Energy, and Stiffness. Acta Biomater.2021, https://doi.org/10.1016/j.actbio.2021.04.021.

19. Sofia, C.; Ramakrishna, S.; Laura, T.; Maria, C. A. Cell Signalling and Biomaterials Have A Symbiotic Relationship as Demonstrated by A Bioinformatics Study: The Role of Surface Topography. Curr. Opin. Biomed. Eng.2021,17, 100246, https://doi.org/10.1016/j.cobme.2020.09.002.

20. Topuz, M.; Dikici, B.; Gavgali, M. Titanium-Based Composite Scaffolds Reinforced with HydroxyapatiteZirconia: Production, Mechanical and In-Vitro Characterization. J. Mech. Behav. Biomed. Mater.2021, 118, 104480, https://doi.org/10.1016/j.jmbbm.2021.104480.

21. Alaneme, K. K.; Oluwaseun, P. A.; Samuel, R. O.; Oluwasegun, E. F.; Peter, A. O. Densification Characteristics, Microstructure and Wear Behaviour of Spark Plasma Sintering Processed Titanium-Niobium Pentoxide (Ti-Nb2O5) Based Composites. J. King Saud. Univ. Eng. Sci. 2020,https://doi.org/10.1016/j.jksues.2020.10.005.

22. Mahmud, N. N.; Sulong, A. B.; Sharma, B.; Ameyama, K. Presintered Titanium-Hydroxyapatite Composite Fabricated via PIM Route. Metals2021, 11, 318,https://doi.org/10.3390/met11020318.

23. Bandyopadhyay, A.; Dittrick, S.; Gualtieri, T.; Wu, J.; Bose, S. Calcium Phosphate-Titanium Composites for Articulating Surfaces of Load-Bearing Implants. J. Mech. Behav. Biomed. Mater. 2016, 57, 280288,https://doi.org/10.1016/j.jmbbm.2015.11.022.

24. Suryanarayana, C. Mechanical Alloying and Milling. Prog. Mater. Sci. 2001, 46, 1184,https://doi.org/10.1016/S0079-6425(99)00010-9.

25. Suchank, W.; Yoshimura, M. Processing and Properties of Hydroxyapatite-Based Biomaterials for use as Hard Tissue Replacement Implants. J. Mater. Res.1998, 13, 94-117,https://doi.org/10.1557/JMR.1998.0015.

26. Attar, H.; Ehtemam-Haghighi, S.; Nicolas, S.; Damon, K.; Dargusch, M. S. Additive Manufacturing of LowCost Porous Titanium-Based Composites for Biomedical Applications: Advantages, Challenges and Opinion for Future Development. J. Alloy. Compd. 2020, 827, 154263,https://doi.org/10.1016/j.jallcom.2020.154263.

27. Praveen Kumar, N.; Naveen, Ch.; Sujatha, D.; Anandarao, D.; Naga Sireesha, J.; Anand Kumar, S.; Siva, I.; Venkateswarlu, B.; Jagannatham, M.; Ratna Sunil, B. Developing Composites of ZE41 Mg Alloy - Naturally Derived Hydroxyapatite by Friction Stir Processing: Investigating In-Vitro Degradation Behavior. Mater. Technol. Adv. Perform. Mater. 2018, 33, 603-611,https://doi.org/10.1080/10667857.2018.1483470.

28. Han, C.; Wang, Q.; Song, B.; Li, W.; Wei, Q.; Wen, S.; Liu, J.; Shi, Y.; Microstructure and Property Evolutions of Titanium/Nano-Hydroxyapatite Composites In-Situ Prepared by Selective Laser Melting. J. Mech. Behav. Biomed. Mater. 2017, 71, 85-94,https://doi.org/10.1016/j.jmbbm.2017.02.021.

29. Kokubo, T.; Takadama, H. How Useful is SBF in Predicting In-Vivo Bone Bioactivity?. Biomaterials2006, 27, 2907-2915,https://doi.org/10.1016/j.biomaterials.2006.01.017.

30. Ratna Sunil, B.; Sampath Kumar, T. S.; Chakkingal, U.; Nandakumar, V.; Doble, M. Nano-Hydroxyapatite Reinforced AZ31 Magnesium Alloy by Friction Stir Processing: A Solid State Processing for Biodegradable Metal Matrix Composites. J. Mater. Sci. Mater. Med.2014, 25, 975-988,https://doi.org/10.1007/s10856-0135127-7.

31. Webster, T. J.; Ergun, C.; Doremus, R. H.; Siegel, R. W.;Bizios, R. Specific Proteins Mediate Enhanced Osteoblast Adhesion on Nanophase Ceramics. J. Biomed. Mater. Res.2000, 51, 475483,https://doi.org/10.1002/1097-4636(20000905)51:3\%3C475::AID-JBM23\%3E3.0.CO;2-9.

32. Kim, H. M.; Himeno, T.; Kawashita, M.; Kokubo, T.; Nakamura, T. The Mechanism of Biomineralization of Bone-Like Apatite on Synthetic Hydroxyapatite: An In Vitro Assessment. J. Royal. Soc. Interface.2004, 1, 17-22,https://doi.org/10.1098/rsif.2004.0003.

33. Ratna Sunil, B.; Sampath Kumar, T.S.; Chakkingal, U.; Nandakumar, V.; Doble, M. Friction Stir Processing of Magnesium - Nanohydroxyapatite Composites with Controlled In Vitro Degradation Behavior. Mater. Sci. Eng. C2014, 39, 315-324,https://doi.org/10.1016/j.msec.2014.03.004. 